\title{
Cultura digital. Entredichos en una ciudadanía de dispositivos y aplicaciones.
}

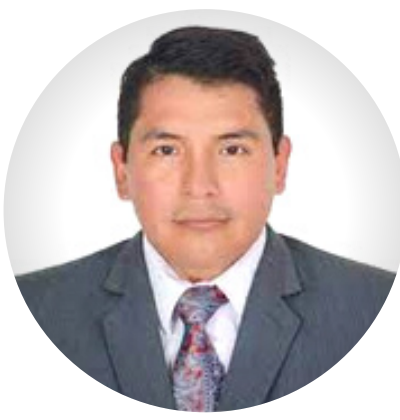

\section{MIGUEL LAURENTE CÁRDENAS}

http://orcid.org/0000-0003-0566-4992

Bachiller en Educación por la Universidad Nacional Mayor de San Marcos, Magíster en Educación por la Universidad César Vallejo, Lima, Perú. Docente de la Universidad Nacional Mayor de San Marcos y del Instituto de Formación Bancaria. Investigador del impacto de las tecnologías digitales en el rubro educativo.

carlos.laurente.c@gmail.com

Resumen. Este estudio tuvo como propósito mostrar un aspecto del comportamiento humano en la cultura digital en la que vive la sociedad contemporánea, donde actividades cotidianas como hacer llamadas, enviar mensajes, compartir documentos, buscar información, realizar compras o pedir un taxi tienen en común el uso de dispositivos tecnológicos y plataformas digitales. Esta investigación se enmarca bajo los parámetros de un estudio de carácter descriptivo, donde la identificación y descripción de las características del fenómeno son el epicentro de la investigación. Una sociedad digital evidencia diversas características. Según la agencia We Are Social (2019), el 67\% de la población mundial cuenta por lo menos con un Smartphone, y el 57\% tiene acceso a internet. Ante esta situación es necesario reflexionar sobre cómo se conduce la sociedad global respecto el uso de dispositivos y aplicaciones tecnológicas. Una cultura digital va más allá de utilizar las TIC más novedosas, es también poseer competencias digitales, que ayudarán que la sociedad sea más crítica y reflexiva.

Palabras clave: Cultura digital, internet, Smartphone, competencia digital.

\section{Interactuando en medios digitales}

El aumento en el uso de dispositivos y entornos digitales se ha convertido en un fenómeno latente en las sociedades. Asimismo, la interacción de las personas al realizar actividades cotidianas a través de aplicativos móviles se ha incrementado notablemente. Según el portal web We Are Social (2021), en el año 2020, el incremento de personas que hacen uso de redes sociales a través del Smartphone fue de 316 millones nuevos usuarios en el planeta (González, 2019).

Por otro lado, no solo creció el uso de dispositivos móviles, sino también la red que brinda soporte tecnológico a estas interacciones. El crecimiento de internet ha permitido que las comunicaciones se operen a través de múltiples plataformas, las cuales son interactivas y han cubierto aquellas brechas geográficas que en décadas anteriores era impensado sobrepasarlas (Castells, 2013). De misma forma, la adquisición de mejores planes de telefonía móvil se ha incrementado notablemente, en especial, aquellas que ofrecen mayor tiempo de conectividad para el Smartphone, el cual, junto al ser humano ha creado una relación casi simbiótica, donde la idea de desprenderse del móvil puede tener consecuencias hasta depresivas. (Cobo, 2019) Lo mencionado anteriormente es concordante con lo manifestado por el INEI al afirmar que, en el 2018, el $82 \%$ de ciudadanos peruanos de zonas urbanas accedieron a internet a través de sus Smartphones, una cifra bastante alta, la cual, a su vez, en la actualidad se habría incrementado. Toda persona es libre para interactuar en la web como mejor le convenga, sin embargo, es necesario tener en cuenta el valor de productividad y funcionalidad que se está dando a la interacción que se realiza en entornos virtuales (Sánchez et al., 2019).

En una sociedad que interactúa con mayor facilidad en espacios digitales, los términos sobrexposición e hiperconexión salen a relucir; sin embargo, no se puede definir cuál debería ser el tiempo permitido en la que una persona debe estar conectada (Cobo, 2019). Por tal razón, la autorregulación como capacidad de establecer límites respecto al cuánto y cómo utilizar el Smartphone y los entornos web es fundamental 
(Castañeda, Esteve, \& Adell, 2018). Del mismo modo, el establecimiento educativo de competencias digitales, donde la aptitud crítica - reflexiva en el uso de herramientas y dispositivos tecnológicos permita la instauración de una cultura digital responsable en una sociedad que cada día se vuelve más tecnológica (Martínez, Sádaba, \& Serrano, 2018).

\section{La mirada y el black mirror en una sociedad digital}

Según la psicología, la mirada es un factor fundamental cuando se interactúa con otra persona; asimismo, es considerado como un aspecto básico del lenguaje corporal (Villamil, 2009). Sin embargo, este contacto visual entre personas es menos constante ya que como competidor se encuentra la contemplación prolongada al Smartphone, donde las pantallas fungen ser más interesantes que una conversación o la observación del entorno inmediato (Aveiga, Ostaiza, Macías, \& Macías, 2018). Es evidente notar que la gran mayoría de usuarios de transporte público interactúa con sus móviles en todo el trayecto de su viaje; del mismo modo en el que comensales esperan sentados y navegando en internet hasta que llegue su orden. En las acciones antes mencionadas las probabilidades de sufrir algún percance son casi nulas, sin embrago, si al contacto visual con el smartphone se agrega la acción de movilizarse a pie por las calles, el riesgo de sufrir algún accidente se incrementa y más aún si se maneja algún vehículo.

Actualmente, el uso del smartphone mientras se está conduciendo un vehículo motorizado es constituido una falta grave según el Reglamento Nacional de Tránsito, ya que esta acción impide que el conductor tenga las dos manos en el volante (Sutran, 2014). Sin embargo, no solo las manos sobre el volante del transporte son el problema, sino también la inadvertencia que se genera cuando se conduce y se utiliza un teléfono inteligente al mismo tiempo. Según la Policía Nacional del Perú (PNP), en el 2017, el 25\% de los accidentes de tránsito registrados fueron por la combinación del uso del celular y conducir un vehículo (Perú21, 2018). Es decir, esta práctica produjo 22,042 accidentes, un aproximado de 60 de estos hechos diariamente (Policia Nacional del Perú, 2018).

Según lo mencionado, es necesario reflexionar respecto la conducta que está adoptando la sociedad en el uso de dispositivos digitales. A diario es común observar personas interactuando con las pantallas de sus teléfonos e ignorando lo que pasa a su alrededor. Este fenómeno ha dado lugar al esta- blecimiento de nuevos términos como el de "smartphone zombies" o "phonbies" nombre que se ha dado a aquellas personas que viven al servicio de su smartphone (Cobo, 2019). Toda sociedad intenta caminar hacia el desarrollo, ya sea económico, social, cultural o en educación. Sin embargo, deben entretejerse competencias básicas y transversales en la ciudadanía, tales como las competencias digitales, las cuales según European Parliament and the Council (2006), son consideradas fundamentales para cada individuo en la sociedad.

Si bien, la mirada como aspecto simbólico de la atención que brindamos al interrelacionarlos con los demás ha sido afectada por el uso desmedido de los dispositivos digitales, dando lugar al trastorno del ningufoneo. La mirada en el aspecto fisiológico también ha sido afectada. El uso no regulado del smartphone u otro dispositivo, está ocasionando afecciones como el ojo seco y el parpadeo ocular constante en niños que estuvieron más de 60 minutos diarios interactuando con dispositivos (Hervias, Malca, Cruz, Huansi, \& Morales, 2018). Según lo mencionado, es necesario crear consciencia respecto el uso mesurado de los dispositivos digitales estableciendo límites para el desarrollo de una ciudadanía digital responsable.

\section{Libertad de expresión en la era digital}

A lo largo de la historia, cada una de las sociedades ha adoptado diversas medidas con el fin de promover el orden y protección a los ciudadanos. Asimismo, el otorgamiento de derechos que posee cada persona desde su nacimiento ha sido una de las propuestas que más ha ayudado en el establecimiento de sociedades democráticas (Torres \& Silva, 2019). Cada individuo nace con múltiples derechos, como el derecho a la vida, a la nacionalidad, a la identidad personal, al respeto de su dignidad como persona, a la no discriminación, a la libertad de opinión y pensamiento, entre otros. Cada uno de estos son considerados fundamentales en el fortalecimiento de las sociedades (Convención Americana de Derechos Humanos, 1969).

Para que los derechos que tiene la persona estén posicionados en el sitial donde se encuentran han transcurridos múltiples conflictos, inconformidades y sobre todo muchos años de espera para que exista un consenso respecto a los derechos que actualmente son considerados como fundamentales (Bernal 2007). La denominada era digital permite tener acceso masivo a grandes cantidades de datos e información de cualquier índole, es así que toda persona tiene el derecho de 
investigar lo que desee, así como difundir las opiniones y pensamientos a los que llegue a causa de sus investigaciones (Comisión Interamericana de Derechos Humanos, 2007).

Actualmente, internet se ha convertido en el medio principal para que la ciudadanía ejerza su libertad de expresión y pensamiento (Castells, 2013). Asimismo, las redes sociales se comportan como una colosal plataforma donde cada uno de los usuarios vierte sus comentarios y replica otros que responden a los suyos (Gorbea \& Paneque, 2018). Del mismo modo, permite que las personas puedan crear perfiles y tener cientos o miles de seguidores con acceso a leer las ideas que divulguen; además, las redes sociales tienen un alto poder de convocatoria (Cela, Parras, \& Romero, 2019). Ante ello puede afirmarse que este es análogo a la función conativa del lenguaje, donde el mensaje se centra en el receptor, intentado persuadir a que piense o actúe como desea el emisor.

La libertad de expresión, incluso cuando se ejerza a través de internet, no constituye un derecho absoluto e ilimitado, sino que debería ser objeto de ciertas auto-restricciones que deberán definirse con precisión. Por tal razón, al realizar publicaciones y expresarse en redes sociales o por algún otro medio digital, es necesario entender que la libertad de expresión es un derecho que permite manifestar pensamientos e ideas con total libertad; sin embargo, esta no debe promover el insulto, la vejación o comentarios que trastocan el honor y dignidad del ser humano.

\section{La información en la era digital.}

Descifrar la cantidad de información contenida en la web, sería una misión casi imposible, ya que esta se actualiza, agrega y caduca a cada momento. Por ejemplo, en el 2015 y 2016 se publicaron 4,602,908,743 de artículos científicos (Banco Mundial, 2016), una gran cantidad de información accesible a todos aquellos que se conecten a internet. Sin embargo, esta no es toda la información que existe en la web, ya que se tendría que tomar en cuenta cada red social, blog, página web, plataforma o cada mundo virtual para contabilizar de algún modo la información establecida en el ciberespacio.

En la actualidad, las nuevas tecnologías e internet han puesto en evidencia dos posturas que el usuario puede tener respecto la información. La primera, concebida como todos aquellos informes, noticias, programas, recursos y herramientas que internet ofrece respecto a cualquier temática que se desea investigar. La segunda, respecto a toda información que el usuario ofrece de sí mismo y de manera pública en sus cuentas web; donde cada persona al utilizar dispositivos y navegar a través de la red deja un rastro digital imborrable donde no existen anónimos en la web (Cobo, 2019).

Un rasgo que distingue a la sociedad actual es la masificación de información. El fenómeno denominado sociedad de la información tiene impacto sobre el contexto económico y productivo de una nación (Quiroga, Gutierrez, \& Mercader, 2018). La abundancia de información ha planteado una cuestión ineludible respecto a la confiabilidad de la información expuesta en internet. Toda persona que realiza alguna búsqueda en la web tendrá incontables posibilidades de acceder a publicaciones respecto lo que investiga. Por tanto, toda búsqueda en el ciberespacio debe considerar el propósito de la información, el momento de su publicación, el espacio donde fue publicado, el autor que publica y el posible sesgo que se le ha dado (Kriscautzky \& Ferreiro, 2017).

Otro aspecto a tener en cuenta son los algoritmos informáticos que descifran la interacción de las personas en la web y buscan patrones respecto a los sitios visitados con el fin de proponer coincidencias similares a las que la persona ha accedido (Brand, Kammerer, van Meeuwen, \& van Gog, 2017). Captar la atención del internauta, es actualmente el principal objetivo para que el modelo de negocio basado en la manipulación de datos que ofrece el usuario se siga sosteniendo (Cobo, 2019; Harari, 2016).

La ciudadanía contemporánea se encuentra en un contexto donde la masificación de los datos del usuario de internet son una jugosa recompensa para empresas que los comercializan. Escándalos como el de Facebook, revelados en el 2018 por el Diario New York Times, muestran que los datos personales tienen incidencia incluso en los destinos políticos de las naciones. Por tanto, es indispensable que cada ciudadano evalúe de manera juiciosa, qué es lo que hace con la información proveniente de la web y qué con la información que el mismo usuario le ofrece a internet.

\section{Conclusiones}

El establecimiento de una cultura digital en cada una de las sociedades es innegable; sin embargo, esta cultura debe fundamentarse bajo parámetros de competencias digitales, donde valores como el respeto, responsabilidad, juicio crítico - reflexivo y sobre todo autorregulación sean transversales en el 
comportamiento de cada internauta. Si bien los dispositivos y aplicaciones digitales son herramientas atractivas y funcionales para el desenvolvimiento cotidiano, estas necesitan ser gestionadas de manera apropiada, de lo contrario la supuesta solución (tecnología) podría convertirse en el problema.

Asimismo, si el ciudadano no sabe regular de manera adecuada el consumo diario hacia internet, la sociedad se estará encaminando hacia problemas sustanciales como el ningufoneo o la nomofobia, trastornos que irán alojándose en comunidades donde la autorregulación es escaza y las competencias digitales no se han establecido en los currículos educativos.

Las brechas digitales han ido disminuyendo con el paso de los años, esto ha generado que el acceso y la oportunidad de publicar opiniones libres en la web se incremente. Sin embargo, la idea de libertad de expresión en los medios digitales debe ir acompañada de la responsabilidad de no vulnerar ninguno de los derechos de la persona. La libertad

\section{Referencias}

Aveiga, V., Ostaiza, J., Macías, X., \& Macías, M. (2018). Uso de la tecnología: entretenimiento o adicción. Caribeña de Ciencias Sociales, (agosto).

Banco Mundial. (2016). Artículos en publicaciones científicas y técnicas | Data. Recuperado 6 de diciembre de 2019, de DataBank website: https://datos.bancomundial.org/indicador/IP.JRN.ARTC.SC

Brand, S., Kammerer, Y., van Meeuwen, L., \& van Gog, T. (2017). Source evaluation of domain experts and novices during Web search. Journal of Computer Assisted Learning, 33(3), 234-251. https://doi.org/10.1111/jcal.12162

Castañeda, L., Esteve, F., \& Adell, J. (2018). Why rethinking teaching competence for the digital world? Revista de Educacion a Distancia, (56), 1-20. https://doi.org/10.6018/red/56/6

Castells, M. (2013). El impacto de internet en la sociedad: una perspectiva global. Turner, 97(4), 472.

Cela, J., Parras, A., \& Romero, L. (2019). Uso de las redes sociales en diplomacia, política y relaciones internacionales. Análisis de la información publicada en las versiones online de dos periódicos españoles: El País y La Vanguardia. Estudios sobre el Mensaje Periodístico, 25(2),

711-726.

https://doi.org/https://dx.doi.org/10.5209/esmp.64798 de opinión es un derecho que legitima al ciudadano a manifestar pensamientos, ideas y posturas, pero no debe promover el insulto o el desprestigio, así como la propalación de comentarios lesivos o vejatorios. Una ciudadanía digital debe alinearse con una cultura de paz, entendiendo que los derechos de una persona terminan cuando empieza el derecho de los demás.

Finalmente, la información contenida en internet seguirá incrementándose, sin embargo, una sociedad con mayor cantidad de información no es una sociedad más informada. Es necesario construir una sociedad que gestione la información, donde las competencias digitales, la capacidad de evaluar, reflexionar y discernir sean los soportes para el establecimiento de una cultura digital más justa, veraz e informada.
Cobo, C. (2019). Acepto las condiciones: Usos y abusos de las tecnologías digitales (Febrero 20). España: Fundación Santillana. González, J. (2019). Narrativas de la vida digital: la abyección del cuerpo en la red. Vitam. Revista de Investigación en Humanidades, (2), 64-72. https://doi.org/10.35461/vitam.v0i2.22

Gorbea, S., \& Paneque, D. (2018). Identification of Patterns of Informative Behavior in the Texts with the Social Networks Analysis. e-Ciencias de la Información, 8(1). https://doi.org/10.15517/eci.v8i1.28005

Harari, Y. (2016). Homo Deus. En Debate. Barcelona. España. Hervias, B. G., Malca, K., Cruz, Y. K., Huansi, N. L., \& Morales, J. (2018). Uso de dispositivo móvil en niños preescolares de un distrito de Lima. Rev Peru Salud Pública Comunitaria, 1(2), 61-65.

Kriscautzky, M., \& Ferreiro, E. (2017). Evaluar la confiabilidad de la información en Internet: cómo enfrentan el reto los nuevos lectores de 9 a 12 años. Revista Perfiles Educativos, 11(159), 16-34. http://www.scielo.org.mx/scielo.php?pid=S0185-

26982018000100016\&script=sci_arttext\&tlng=en

Martínez, M. cristina, Sádaba, C., \& Serrano, J. (2018). Desarrollo De Competencias Digitales En Comunidades Virtuales: Un Análisis De «Scolartic». Prima social, (20), 130-159. https://revistaprismasocial.es/article/view/2318

Policia Nacional del Perú. (2018). Accidentes de tránsito 2006 2017.

http://www.mtc.gob.pe/cnsv/documentos/accidentesTransito_20062017.pdf 
Quiroga, A., Gutierrez, E., \& Mercader, A. (2018). Las estrategias de búsqueda, selección y validación de la información en internet como una competencia crítica en la sociedad del conocimiento. Un análisis en adolescentes y jóvenes estudiantes salteños. Revista en línea de la Maestría en Estudios Latinoamericanos FCPyS-UNCuyo, 7(Marzo 2018-Marzo 2019), 1-13.

Sánchez, R., Novillo, M., Arigita, A., Costa, Ó., Barrientos, A., \& Pericacho, F. (2019). Carencias y limitaciones que afectan al asentamiento de la realidad virtual como tecnología de referencia en la sociedad actual. Espacios, 40(10), 11.

Sutran. (2014). Texto único ordenado del Reglamento Nacional de Tránsito-Código de Tánsito. http://www.sutran.gob.pe/wpcontent/uploads/2015/08/D_-NRO_016-2009-MTC_AL_05.05.14.pdf Torres, A. D., \& Silva, R. (2019). Aprender a Convivir en Educación Superior desde la Práctica Docente, para una Sociedad Democrática. Formación universitaria, 12(2), 51-62. https://doi.org/10.4067/s0718-50062019000200051

Villamil, M. Á. (2009). Fenomenología de la mirada. Discusiones
filosóficas,
10(14),
97-118.

http://www.scielo.org.co/pdf/difil/v10n14/v10n14a06.pdf

\section{Cómo citar este artículo:}

Laurente, C. (2021). Cultura digital. Entredichos en una ciudadanía de dispositivos y aplicaciones. Futuro Hoy, 2(4), 38-42. https://doi.org/10.52749/fh.v2i4.9

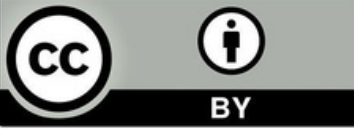

Esta obra está bajo licencia internacional Creative Commons 4.0 Reconocimiento 4.0. 